\title{
Gaseous Pollutants From A Small-Scale Aerobic Biological Treatment Facility: Odor And Carcinogenic Risk Assessment
}

\section{Xinhong Xu}

Navy

Kexian Li

Navy Environmental Health Center: Navy and Marine Corps Public Health Center

Fan Lü

Navy

Pinjing He

Tongji University

Jingjing Fang ( $\sim$ f18916873201@163.com )

Navy https://orcid.org/0000-0002-4942-0976

\section{Research Article}

Keywords: small scale, aerobic biological treatment, gasous polltants, odor assessment, carcinogenic risk assessment

Posted Date: August 23rd, 2021

DOI: https://doi.org/10.21203/rs.3.rs-806113/v1

License: (c) (i) This work is licensed under a Creative Commons Attribution 4.0 International License. Read Full License 


\section{Abstract}

BACKGROUND: Biological treatment technology is good for the recovery of resources and energy from municipal solid waste (MSW) and cutting down biodegradable components in landfill waste. Recently, the aerobic biological treatment of MSW has increased in rural areas of China. These facilities are usually open setup and closed to nearby residents, and complaints tend to be received regarding odorous gases. A semi-in-vessel setup facility was occured in recent years, and its impact on the environment and personnel is not clear.

RESULTS: Ammonia was the predominant compound released from the windrow and its concentration was one order of magnitude higher than those of other compounds. Terpenes and reduced sulfur compounds (RSCs) persisted throughout the entire active fermentation process, with only slight decreases. The biofilter pool had a greater odor impact on the surrounding neighborhood than the waste unloading and sorting operation. The concentrations of most compounds were reduced by the biofilter pool. Ten major substances that caused odors at the periphery of the facility were analyzed, where most comprised RSCs. The odor impact of the facility was low but it was associated with a carcinogenic risk to the operators, thereby indicating the need to improve personal protection.

Conclusions: Large amounts of ammonia and volatile organic compounds were released from the composting units, but they had a low odor impact on the environment because of the semi-in-vessel setup. The odor impact of the facility was low but it was associated with a carcinogenic risk to the operators. This technology can be popularized in rural areas.

\section{Background}

Biological treatment technology is good for the recovery of resources and energy from municipal solid waste (MSW) and cutting down biodegradable components in landfill waste. Recently, the aerobic biological treatment of MSW has increased in rural areas of China. These facilities are usually close to nearby residents, and complaints tend to be received regarding odorous gases. Ammonia is the predominant gaseous pollutant with emissions of around $18-1150 \mathrm{~g} / \mathrm{t}$ waste [1]. The concentration of ammonia in the exhaust gas from sludge composting facilities can be as high as can be as high as 700 $\mathrm{mg} / \mathrm{m}^{3}$ [2]. Volatile organic compounds (VOCs) are also one of typical air pollutants, with concentrations in the air around MSW composting facilities ranging from $8 \mathrm{mg} / \mathrm{m}^{3}$ to $16 \mathrm{mg} / \mathrm{m}^{3}$ [3]. Rodriguez et al. [4] researched the influence of the operating technology to $\mathrm{VOC}$ release, such as moisture, oxygen, and C:N ratios. They found that the most important factor was the $\mathrm{C}: \mathrm{N}$ ratio, then was the internal oxygen and moisture contents of the windrow.

The emission patterns of gaseous pollutants during mechanical processes, such as waste sorting and shredding, differ significantly from those in aerobic biological treatment processes. Stirring and crushing processes can strip some compounds, especially xenobiotic organics, from the surface of the waste and make them readily volatilized [5]. Toluene and xylene are the dominant VOCs in the shredding, mixing, 
and sorting areas of composting facilities. Some studies reported that these aromatics originated from the decomposition of polymer and solvents [6], whereas others have shown that these aromatics compounds are released from raw materials rather than intermediate products of waste biodegradation. Volatile fatty acids (VFAs) can be produced by the hydrolysis and anaerobic digestion of carbohydrates [7-8], fats, and proteins in waste, and they can accumulate when inadequate oxygen is supplied during aerobic biodegradation [9]. The olfactory threshold of VFAs is low, which has a great impact on the environment.

Sulfur compounds, nitrogen-containing compounds and terpenes have strong pungent odor also, so the emission of these gas pollutants will have odor impact on nearby communities. In the process of refuse composting, incomplete or inadequate ventilation will lead to the release of hydrogen sulfide and other malodorous substances [10-11]. Fang et al. [12] found that limonene, dimethyl sulfide, dimethyl disulfide and $\mathrm{a}$ - pinene are the main odorants in municipal solid waste composting facilities. Tsai et al. [13] studied the kitchen waste composting facilities and found that the concentrations of ammonia, dimethyl sulfide and hydrogen sulfide had a logarithmic relationship with odor intensity, while the concentrations of ethylbenzene, acetic acid and p-toluene had a linear relationship with odor intensity. This result tells us that reducing odor intensity of ammonia, dimethyl sulfide and hydrogen sulfide is much more difficult than other pollutants. It is reported that the odor of trimethylamine has high persistence and low odor threshold. Therefore, if the odor source contains trimethylamine, the influence range and distance of the source are larger than others [14].

The present study investigated the odor compounds emitted from a small-scale MSW aerobic biological treatment facility as well as assessing the odor impact and carcinogenic risk for the operators. Based on calculations of the theoretical odor concentrations, the main odor compounds were identified in various treatment processes and the environmental quality was evaluated.

\section{Methods}

\subsection{Site description and sampling location}

The study site was located in Shanghai Chong Ming Island, with a capacity of approximately $0.6-2$ ton/day, and the service area comprising a community of 4000 resident was $100 \mathrm{~m}$ away from the facility. The facility comprised 20 composting units, a biofilter pool, and a sorting area, as shown in Fig. 1. Chopped straw with a length of $2-5 \mathrm{~cm}$ was used as a bulking agent. After removing glass and metal debris, the raw MSW was mixed with the bulking agent at a ratio of 10:1 (w/w) considering that the water content should not be excessively low, and an adequate specific surface area and free air spaces were necessary in the matrix [15]. The characteristics of the raw materials and mixture are presented in Table 1. The volatile solids content was analyzed by heating samples to a constant weight at $550^{\circ} \mathrm{C}$ in a muffle furnace. The oxygen concentration and temperature at the core of the windrow were monitored using a probe (CYS-1; Xuelian Co., Shanghai, China). The elemental compositions of the freeze-dried samples were measured using an elemental analyzer (Vario EL III, Elementar Analysensysteme GmbH, 
Langenselbold, Germany). Active fermentation (static composting-like process) occurred for 20 days in a closed composting unit with controlled aeration and gas collection, as well as treatment with a biofilter.

Odorous gas sampling was conducted during waste loading, unloading, and sorting. Three sampling points were located in the sorting area, and upwind and downwind of the periphery of the facility. Sampling was also conducted at the same points when the facility was not in operation in order to conduct comparisons. One point was located in the biofilter pool when the ventilation process started. Inside the composting units, gas and solid sampling were conducted after 1, 3, 5, 7, 10, 15, and 20 days during the active fermentation phase. The wind speed during the sampling period was $3.6 \mathrm{~m} / \mathrm{s}$ and the temperature was $24^{\circ} \mathrm{C}$. The relative humidity was approximately $55-65 \%$. In total, seven chemical classes and 51 substances were determined in the gas samples, including ammonia, reduced sulfur compounds (RSCs), aromatics, terpenes, alcohols, carbonyl compounds, and VFAs.

Table 1

Characteristics of the raw materials and mixture feedstock in the tested composting unit.

\begin{tabular}{|lllll|}
\hline & MSW & Straw & Mixture $^{\mathrm{a}}$ & Mixture $^{\mathrm{b}}$ \\
\hline Water content, \% by wet mass & $74.4 \pm 2.7$ & $8.72 \pm 0.45$ & $70.7 \pm 1.3$ & 68.4 \\
\hline VS, \% by dry mass & $79.7 \pm 1.6$ & $88.6 \pm 0.3$ & $84.3 \pm 1.1$ & 86.3 \\
\hline C:N ratio by dry mass & $20.5 \pm 1.8$ & $41.5 \pm 2.4$ & $17.1 \pm 2.9$ & 17.8 \\
\hline Propotion (wet mass, w/w) & $10 / 11$ & $1 / 11$ & - & - \\
\hline Weight (wet mass, kg) & 550 & 55 & 605 & 605 \\
\hline a The value was based on determination. & & & \\
\hline b The value was based on calculation. & & & \\
\hline
\end{tabular}

\subsection{Analysis of gas samples}

Several methods were used to test different target gaseous pollutants, as showing in Table 2. These methods included sorbent concentration, cold trap concentration, derivatization concentration, gas chromatography method, liquid chromatography and colorimetric method. 
Table 2

Methods were used to measure different target gaseous pollutants.

\begin{tabular}{|lll|}
\hline $\begin{array}{l}\text { Pre-concentration } \\
\text { method }\end{array}$ & Test method & $\begin{array}{l}\text { Target gaseous } \\
\text { pollutants. }\end{array}$ \\
\hline- & colorimetric tube & Ammonia \\
\hline Sorbent & $\begin{array}{l}\text { Gas chromatography with flame ionization } \\
\text { detection (GC-FID) }\end{array}$ & $\begin{array}{l}\text { Volatile fatty acids } \\
\text { (VFAs) }\end{array}$ \\
\hline Cold trap & $\begin{array}{l}\text { Gas chromatography with flame ionization } \\
\text { detection (GC-FID) }\end{array}$ & $\begin{array}{l}\text { Aromatics, terpenes, } \\
\text { alcohols }\end{array}$ \\
\hline Cold trap & $\begin{array}{l}\text { Gas chromatography with pulsed flame photometric } \\
\text { detection (GC-PFPD) }\end{array}$ & $\begin{array}{l}\text { Reduced sulfur } \\
\text { compounds (RSCs) }\end{array}$ \\
\hline Derivatization & High-performance liquid chromatography (HPLC) & Carbonyl compounds \\
\hline
\end{tabular}

\subsubsection{Analysis of ammonia using colorimetric tubes}

Ammonia in each sample was detected by colorimetric tubes (GV-100s, GasTec., Kanagawa, Japan). Cut both ends of the colorimetric tube and insert the colorimetric tube into the hand pump in the direction of the arrow. A specific volume of $100 \mathrm{~mL}$ gas was extracted to the colorimetric tubes. Wait several minutes and confirm the completion of the sampling. The lengths of the color changes in the tubes indicated the concentrations of Ammonia.

\subsubsection{GC analysis after cold trap concentration}

The air samples were collected by Tedlar bags (3L, SKC, PA, USA) which were placed in a sealed plastic box. There were two holes on the lid of the plastic box, one was connected with the Tedlar bag, and the other was connected with a vacuum pump. When the box was vacuumized by the pump, the air sample entered to the Tedlar bag through the hole connected with the bag. This will prevent the air pump from contaminating the air samples. The samples were placed for dark storage and transported to the laboratory within 12 hours to minimize the loss of RSCs during storage.

According to the United States Environmental Protection Agency (USEPA) T015 method [16], these air samples were concentrated by cold trap (Entech Instruments Inc., CA, USA) with liquid nitrogen, then detected by GC-FID and GC-PFPD (GC 450, Varian Inc., CA, USA). The injection volume was $100-1000$ $\mathrm{mL}$, according to the actual concentrations. The GC-PFPD and GC-FID parameters were described in detail in our previous study [17].

\subsubsection{GC-FID analysis after sorbent concentration}

Volatile fatty acids in air samples were determined by adsorbent concentration method. Air samples were collected using commercial adsorption tubes (silica gel tubes, SKC, PA, USA). The air flow rate was 2000 $\mathrm{ml} / \mathrm{min}$ and the collection time was $120 \mathrm{~min}$. After sampling, each tube was sealed and transported to the laboratory within 12 hours. Take out the silica gel adsorbent, put it into a $5 \mathrm{ml}$ volumetric flask and 
absorb it with $5 \mathrm{~mL}$ deionized water. After standing for 30 minutes in an ultrasonic apparatus, the supernatant was taken out and analyzed by GC-FID. The operation parameters of FID detection system were the same as our previous study [17].

\subsubsection{HPLC analysis after derivation with DNPH}

Commercial cartridges (Cleanert DNPH-Silica, Agela Technology, Tianjing, China) were used to collect aldehydes in the air samples. Sampling flow rate was $1000 \mathrm{~mL} / \mathrm{min}$ and the sampling time was $2 \mathrm{~h}$ according to EPA method T011A [18]. After collection, the cartridges were sealed and transported to the laboratory within 12 hours. The derived compounds in the cartridges were eluted into a 5-mL volumetric flask with $5 \mathrm{~mL}$ acetonitrile through a solid phase extraction vacuum manifold (Visiprep, Supelco Analytical, Darmstadt, Germany).

\subsubsection{Quality assurance and control}

Five levels of mixed standard gases $\left(50,200,400,800,1600 \mu \mathrm{g} / \mathrm{m}^{3}\right.$, Air Liquid, France) were determined to produce the standard calibration curves. Within the range of $0-1600 \mu \mathrm{g} / \mathrm{m}^{3}$, the correlation was good $\left(R^{2}>0.93\right)$. The detection limit of the instrument is determined by extrapolation of the linear ratio between the minimum peak area and the instrument noise. The concentration of the blank sample was less than 1 $\mu \mathrm{g} / \mathrm{m}^{3}$, indicating that there was no sample contamination during collection, transportation and storage. Ten kinds of repetitive standard gases were determined to evaluate their reproducibility. The relative standard deviation is less than $7 \%$. The standard recoveries of these methods ranged from $81-114 \%$.

\subsection{Theoretical odor concentrations}

Odor threshold concentration of each compound varies greatly and gases with high concentrations do not always contribute strong odors. Odor intensity can be measured by the ratio of its concentration and the odor threshold. When the composition of the odorous gas mixture is known, the theoretical odor concentration $\left(C_{o d}\right)$ of each sample can be estimated based on its analytical concentration and odor threshold according to equations (1) and (2) [19]. The odor intensity of different sample points can be compared by this method.

$$
\begin{aligned}
& C_{\text {od }, i}=\frac{C_{i}}{\mathrm{OT}_{i}} \\
& C_{\text {od }}=\sum_{i=1}^{n} \frac{C_{i}}{\mathrm{OT}_{i}},
\end{aligned}
$$

where $C_{i}$ is the analytical concentration of the $i^{\text {th }}$ compound (ppm); $\mathrm{OT}_{i}$ is the odor threshold value of the $i^{\text {th }}$ compound (ppm), where the $\mathrm{OT}_{\mathrm{i}}$ value for each compound was obtained from a previous study [17]; $\mathrm{C}_{o d, i}$ is defined as the theoretical odor concentration (dimensionless); $n$ is the total number of odorous compounds; and $C_{o d}$ is the sum of the theoretical odor concentrations of $n$ compounds of one sample.

\subsection{Carcinogenic risk assessment}


According to the Integrated Risk Information System of the United States EPA, the carcinogenic risks of gaseous pollutants were evaluated according to the inhalation unit risk (IUR) of carcinogens [20]. The cancer risk assessment was measured based on the lifetime carcinogenic risk (LCR) using Equations (3) and (4). The carcinogenic risk value for a mixed source is the sum of that for each compound, according to Eq. (5). Synergistic and antagonistic effects among substances are not considered.

$L C R i=C D I c a \times I U R \times 1000(3)$

CDIca $=(C i \times I R \times E T \times E F \times E D) /(365 \times B W \times A T)(4)$

$L C R=\sum_{i=1}^{n} L C R i$,

(5)

where IUR is the inhalation unit risk, $\mu \mathrm{g} / \mathrm{m}^{3} ; \mathrm{Ci}$ is the concentration of the gaseous pollutant in the air, $\mathrm{mg} / \mathrm{m}^{3} ; I R$ is the adult respiratory rate, $0.66 \mathrm{~m}^{3} / \mathrm{h} ; E T$ is the daily exposure time of a worker, $8 \mathrm{~h} ; E F$ is the exposure duration, 250 days/year; $E D$ is the exposure duration, 30 years; $B W$ is the body mass, $65 \mathrm{~kg}$; and $A T$ is the average age, 70 years. The parameters were selected based on a previous study [21].

\section{Results And Discussion}

\subsection{Gaseous pollutants inside the composting units}

Inside the composting units, ammonia was the predominant compound and its concentration was one order of magnitude higher than that of other compounds (Fig. 2). The concentration of ammonia was $1300 \mu \mathrm{g} / \mathrm{m}^{3}$ after one day but it increased to $35,000 \mu \mathrm{g} / \mathrm{m}^{3}$ after five days. After composting for 20 days, the concentration of ammonia was still $6000 \mu \mathrm{g} / \mathrm{m}^{3}$. Nitrogen in waste is readily converted into ammonia and this is more likely to occur when the $\mathrm{C}: \mathrm{N}$ ratio is unbalanced. Except for ammonia, the total concentrations of the other chemical classes decreased rapidly from $8181 \mu \mathrm{g} / \mathrm{m}^{3}$ at the start to 224 $\mu \mathrm{g} / \mathrm{m}^{3}$ at the end, thereby indicating that they were mainly released at the start during the active fermentation process. In contrast to the other compounds, ammonia was mainly released in the middle stage. Terpenes and RSCs persisted throughout all stages, although their concentrations decreased slightly, whereas those of other compounds clearly decreased in the later stage.

\subsection{Gaseous pollutants at the periphery of the facility}

The total contents and composition of the odor compounds at the periphery of the facility are shown in Fig. 3 and Fig. 4, respectively. When the facility was not operating, the total concentrations upwind of the periphery, in the sorting area, and downwind of the periphery were $113 \mu \mathrm{g} / \mathrm{m}^{3}, 173 \mu \mathrm{g} / \mathrm{m}^{3}$, and 168 $\mu \mathrm{g} / \mathrm{m}^{3}$, respectively. The total concentration increased when the waste unloading and sorting processes operated, with $138 \mu \mathrm{g} / \mathrm{m}^{3}$ upwind of the periphery, $615 \mu \mathrm{g} / \mathrm{m}^{3}$ in the sorting area, and $246 \mu \mathrm{g} / \mathrm{m}^{3}$ downwind of the periphery. Ammonia was detected only in the biofilter pool at a concentration of 300 $\mu \mathrm{g} / \mathrm{m}^{3}$. Excluding ammonia, the total concentration was $503 \mu \mathrm{g} / \mathrm{m}^{3}$ at this site. At the periphery of the 
facility, the concentrations of acetaldehyde, acrolein, acetic acid, and sulfur compounds (except for $\mathrm{CS}_{2}$ ) were higher than their olfactory thresholds.

The concentration of total pollutants was one or two orders of magnitude higher inside the composting units than outside the units. The concentrations of most compounds were reduced by the biofilter pool, thereby demonstrating that the breakdown of the contaminants in the off-gases was effective. The concentrations of seven odor compounds on the boundary were compared with the national secondary standard limit values (as shown in Table 3 ) and they did not exceed the limit values.

Table 3

The concentration $\left(\mu \mathrm{g} / \mathrm{m}^{3}\right)$ of odor compounds in the boundary compared with the limit value of China (Emission Standards For Odor Pollutants, GB 14554-93).

\begin{tabular}{|c|c|c|c|c|c|}
\hline \multirow[t]{2}{*}{ Compound } & \multirow[t]{2}{*}{ Limit value * } & \multicolumn{4}{|l|}{ Location } \\
\hline & & Upwind-A & Downwind-A & Upwind-B & Downwind-B \\
\hline Ammonia & 1970 & $<300$ & $<300$ & $<300$ & $<300$ \\
\hline Hydrogen sulfide & 37 & ND & 17.9 & 6.2 & 5.8 \\
\hline Methyl mercaptan & 3 & ND & ND & ND & ND \\
\hline Carbon disulfide & 884 & ND & 23.8 & ND & ND \\
\hline Dimethyl sulfide & 25 & ND & 1.3 & 0.9 & ND \\
\hline Dimethyl disulfide & 15 & ND & ND & ND & ND \\
\hline Styrene & 1077 & 15.7 & 7.7 & 0.5 & 11.7 \\
\hline \multicolumn{6}{|c|}{$\begin{array}{l}\text { *the value was secondary standard; ND, not detected; " } A \text { " in } x \text { axis represent sampling without waste } \\
\text { unloading and sorting operation; " } B \text { " represent sampling during waste unloading and sorting } \\
\text { operation. }\end{array}$} \\
\hline
\end{tabular}

The " $C_{o d}$ " values at the periphery of the facility were obtained using Equations (1) and (2), as shown in Fig. 5. Due to their low odor thresholds, RSCs and carbonyls were the main compounds that caused odors. The total " $C_{o d}$ " value at the biofilter pool was 27,475 , which was mostly contributed by RSCs $(99.4 \%)$. The total " $C_{o d}$ " value in the sorting area was 62 without operation and 2022 during operation. Downwind of the periphery, the " $C_{o d}$ " values were 61 without operation and 45 during operation. The odor impact on the neighborhood during the unloading and sorting operation was very slight compared with that at the biofilter pool. Without operation, the major odor substances in the sorting area were acetic acid, acrolein, hydrogen sulfide, xylene, and styrene. During operation, the major odor substances were mostly sulfur compounds, isovaleric acid, and acetaldehyde. The 10 major odor substances detected at the biofilter pool followed the order of: dimethyl trisulfide $(26,222)>$ propyl mercaptan $(425)>$ ethyl 
mercaptan (239) > methyl mercaptan (228) > diethyl sulfide (144) > butanal (134) > hydrogen sulfide (22) $>$ isovaleric acid (16) > acetic acid (11) > dimethyl disulfide (6). The concentrations of odor compounds such as ammonia, RSCs, alcohols, carbonyls, and VFAs were all lower at the periphery of the facility than the corresponding odor thresholds, and thus the odor risk due to the community-scale disposal facility was low for the nearby communities.

\subsection{Major substances associated with carcinogenic risk}

Gaseous pollutants emitted from waste treatment facilities may comprise a carcinogenic risk for workers due to exposure by inhalation [22-24]. Thus, three compounds were selected to evaluate the risk value. Table 4 shows the carcinogenic classifications of the three compounds used in this study to evaluate the carcinogenic risk.

Table 4

Characterization of carcinogenic risk compound from inhalation exposure

\begin{tabular}{|llll|}
\hline Compound & Classification & Tumor site & IUR $\left(\mu \mathrm{g} / \mathrm{m}^{3}\right)$ \\
\hline Acetaldehyde & B2 & Respiratory & $2.20 \times 10^{-6}$ \\
Benzene & A & Hematologic & $2.20 \times 10^{-6}$ \\
\hline Formaldehyde & B1 & Respiratory & $1.30 \times 10^{-5}$ \\
\hline
\end{tabular}

Note: carcinogenic classification method from weight-of-evidence of IRIS; A, carcinogenic to human; B1, possible carcinogen; B2, probable carcinogen; C, carcinogenicity to human body has not been classified; D, may not be carcinogenic.

The USEPA acceptable LCR level for an individual compound is 1.0E-06. According to previous studies $[21,25]$, compounds with LCR values larger than 1.0E-04 and 1.0E-03 are considered "definite risks" and "significant risks," respectively. Compounds with LCR values between $1.0 \mathrm{E}-06$ and 1.0E-05 are considered "probable risks," and those with LCR values between 1.0E-05 and 1.0E-04 are considered "possible risks." Figure 6 shows the LCR values obtained for the waste treatment facility, where the LCR in the facility exceeded the acceptable range of 1.0E-06. The LCR value determined in the sorting area (B) indicated that the sorting operation had a possible carcinogenic risk. The main compound associated with this carcinogenic risk was acetaldehyde during the unloading and sorting operation. When the operation ended, the main compound associated with carcinogenic risk was formaldehyde. Thus, the sorting mode in this facility was a possible carcinogenic risk for the operators. Figure 6 also shows that the LCR determined for the off-gas from the biofilter pool was close to the acceptable value of $1.0 \mathrm{E}-05$. The risk may increase when the efficiency of the facility decreases.

\section{Conclusions}


In this study, ammonia was the dominant compound released from the windrow and its release occurred mainly in the middle stage, unlike most other compounds. Terpenes and RSCs persisted throughout the whole process, with slight decreases in their concentrations. Sulfur compounds, butanal, and isovaleric acid were the main compounds that caused odors at the periphery of the facility. The biofilter pool had a greater impact on the odor in the surrounding neighborhood than the waste unloading and sorting operation. Large amounts of ammonia and VOCs were released from the composting units, but they only had a small impact on the odor in the environment because of the semi-in-vessel setup. The odor impact of the facility was low but it was associated with a carcinogenic risk to the operators, thereby indicating the need to improve protection to the operators.

\section{Declarations}

Ethics approval and consent to participate: Not applicable

Consent for publication: Not applicable

Availability of data and material: Not applicable

Competing interests: The authors declare that they have no competing interests

Funding: This research was funded by the Navy Foundation of China, National Natural Science Foundation of China (NO. 21507161).

Authors' contributions: Xinhong Xu was responsible for writing the paper. Jingjing Fang was responsible for conducting the search. Pinjing He was responsible for screening potentially eligible studies, extracting and analysing data. Kexian Li was responsible for interpreting results, updating reference lists and creating 'Summary of findings' tables. Fan Lü was responsible for extracting and analysing data and interpreting results.

Acknowledgements: Not applicable

\section{References}

1. Clemens J, Cuhls C (2003) Greenhouse gas emissions from mechanical and biological waste treatment of municipal waste. Environ Technol 24(6):745-754

2. Cadena E, Colón J, Sánchez A, Font X, Artola A (2009) A methodology to determine gaseous emissions in a composting plant. Waste Manag 29(11):2799-2807

3. Eitzer BD (1995) Emissions of volatile organic chemicals from municipal solid waste composting facilities. Environ Sci Technol 29(4):896-902

4. Delgado-Rodríguez M, Ruiz-Montoya M, Giraldez I, Cabeza IO, López R, Díaz MJ (2010) Effect of control parameters on emitted volatile compounds in municipal solid waste and pine trimmings composting. J Environ Sci Health A Tox Hazard Subst Environ Eng 45(7):855-862 
5. Komilis DP, Ham RK, Park JK (2004) Emission of volatile organic compounds during composting of municipal solid wastes. Water Res Apr 38(7):1707-1714

6. Pierucci P, Porazzi E, Martinez MP, Adani F, Carati C, Rubino FM (2005) Volatile organic compounds produced during the aerobic biological processing of municipal solid waste in a pilot plant. Chemosphere 59(3):423-430

7. Babel S, Fukushi K, Sitanrassamee B (2004) Effect of acid speciation on solid waste liquefaction in an anaerobic acid digester. Water Res 38(9):2416-2422

8. González G, Urrutia H, Roeckel M, Aspé E (2005) Protein hydrolysis under anaerobic, saline conditions in presence of acetic acid. J Chem Technol Biotechnol 80:151-157

9. Nicolas J, Romain AC, Ledent C (2006) The electronic nose as a warning device of the odour emergence in a compost hall. Sensor Actuat B-Chem 116(1/2):95-99

10. Defoer N, De Bo I, Van Langenhove H, Dewulf J, Van Elst T (2002) Gas chromatography-mass spectrometry as a tool for estimating odour concentrations of biofilter effluents at aerobic composting and rendering plants. J Chromatogr A 970(1-2):259-273

11. Scaglia B, Orzi V, Artola A, Font X, Davoli E, Sanchez A, Adani F (2011) Odours and volatile organic compounds emitted from municipal solid waste at different stage of decomposition and relationship with biological stability. Bioresour Technol 102(7):4638-4645

12. Fang JJ, Zhang H, Yang N, Shao LM, He PJ (2013) Gaseous pollutants emitted from a mechanical biological treatment plant for municipal solid waste: odor assessment and photochemical reactivity. J Air Waste Manag Assoc 63(11):1287-1297

13. Tsai CJ, Chen ML, Ye AD, Chou MS, Shen SH, Mao IF (2008) The relationship of odor concentration and the critical components emitted from food waste composting plants. Atmos Environ 42(35):8246-8251

14. Van Thriel C, Schäper M, Kiesswetter E, Kleinbeck S, Juran S, Blaszkewicz M (2006) From chemosensory thresholds to whole body exposures-experimental approaches evaluating chemosensory effects of chemicals. Int Arch Occup Environ Health 79(4):308-321

15. Hasanimehr MH, Rad HA, Babaee V (2011) Use of Municipal Solid Waste Compost and Waste Water Biosolids with Co-Composting Process. World Applied Sciences Journal 14:60-66

16. USEPA. Compendium Method TO-15, Determination of volatile organic compounds (VOCs) in air collected in specially-prepared canisters and analyzed by gas chromatography/mass spectrometry (GC/MS). Cincinnati, USA. 1999a

17. Fang JJ, Yang N, Cen DY, Shao LM, He PJ (2012) Odor compounds from different sources of landfill: characterization and source identification. Waste Manag 32(7):1401-1410

18. USEPA. Compendium Method TO-11A, Determination of formaldehyde in ambient air using adsorbent cartridge followed by high performance liquid chromatography (HPLC). Cincinnati, USA. $1999 b$

19. Capelli L, Sironi S, Del Rosso R, Centola P, Grande MA (2008) Comparative and critical evaluation of odor assessment methods on a landfill site. Atmos Environ 42(30):7050-7058 
20. USEPA, Integrated risk information system (IRIS) (2019) http://www.epa.gov/iris/index.html

21. Liu J, Zheng G (2020) Emission of volatile organic compounds from a small-scale municipal solid waste transfer station: Ozone-formation potential and health risk assessment. Waste Manag 106:193-202

22. Martí V, Jubany I, Perez C, Rubio X, Pablo JD, Gimenez J (2014) Human Health Risk Assessment of a landfill based on Volatile Organic Compounds emission, immission and soil gas concentration measurements. Appl Geochem 49:218-224

23. Liu Y, Liu Y, Li H, Fu X, Guo H, Meng R (2016) Health risk impacts analysis of fugitive aromatic compounds emissions from the working face of a municipal solid waste landfill in China. Environ Int 97:15-27

24. Wu C, Liu J, Liu S, Li W, Yan L, Shu M (2018) Assessment of the health risks and odor concentration of volatile compounds from a municipal solid waste landfill in China. Chemosphere 202:1-8

25. Bari MA, Kindzierski WB (2017) Concentrations, sources and human health risk of inhalation exposure to air toxics in Edmonton, Canada. Chemosphere 173:160-171

\section{Figures}

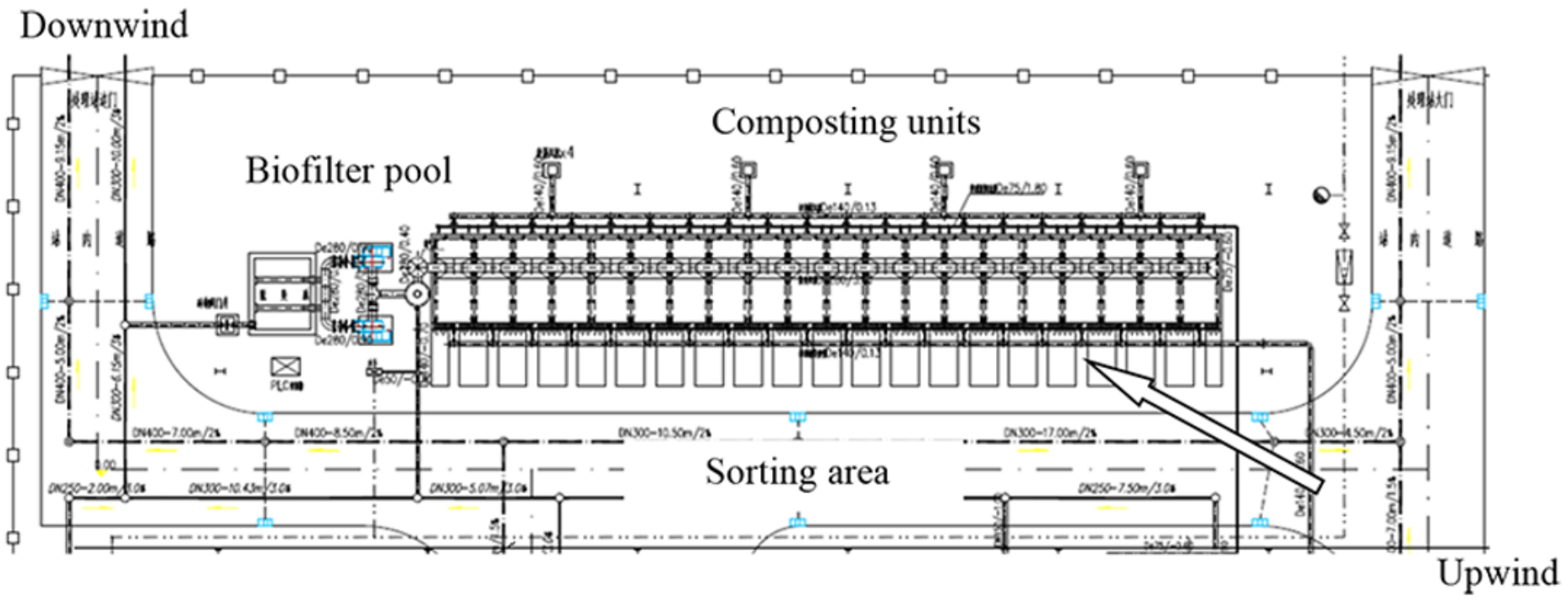

\section{Figure 1}

Schematic diagram of the aerobic biological treatment facilities. 


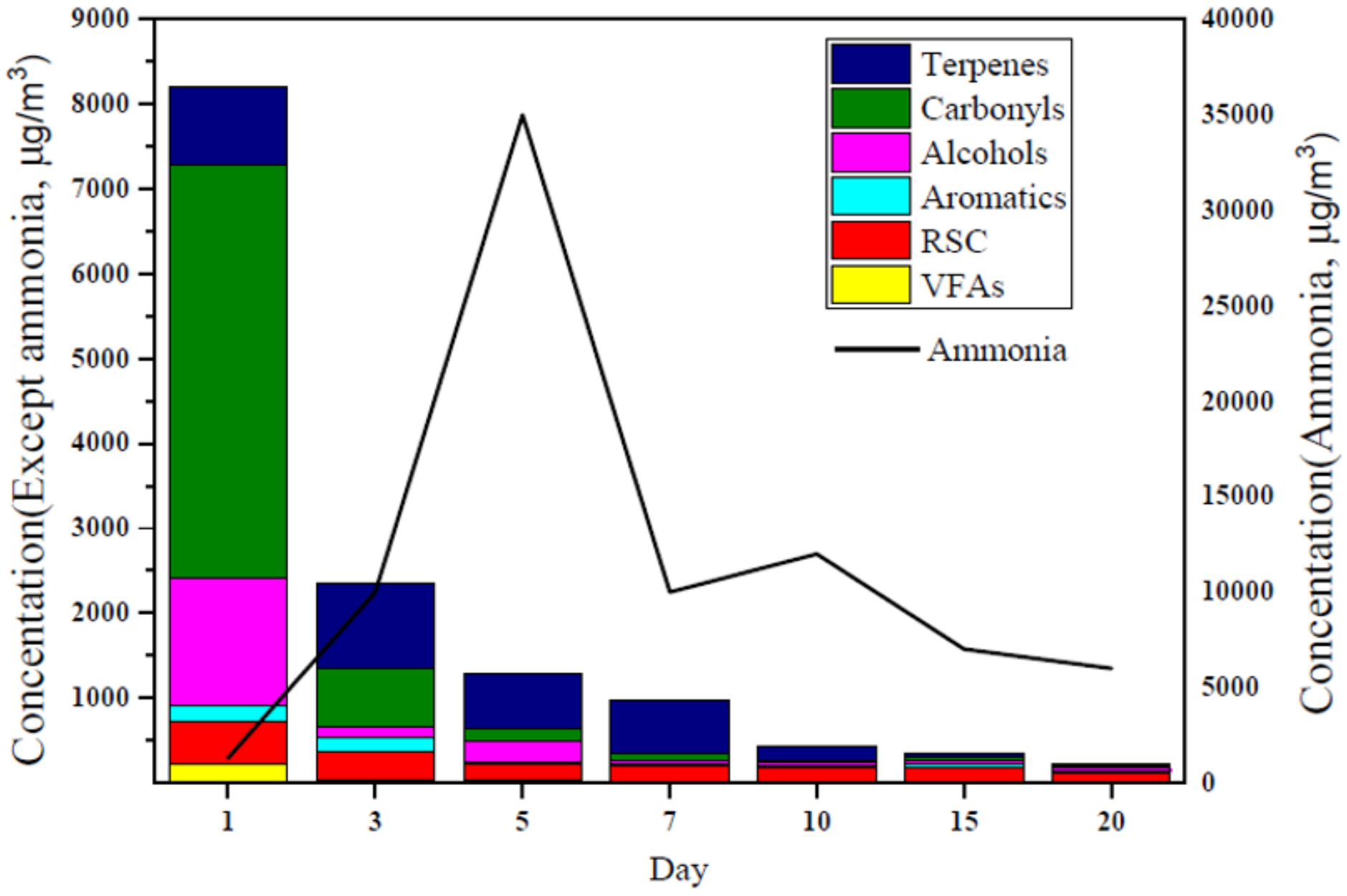

Figure 2

The variation of gaseous pollutant composition with the process in the composting unit. 


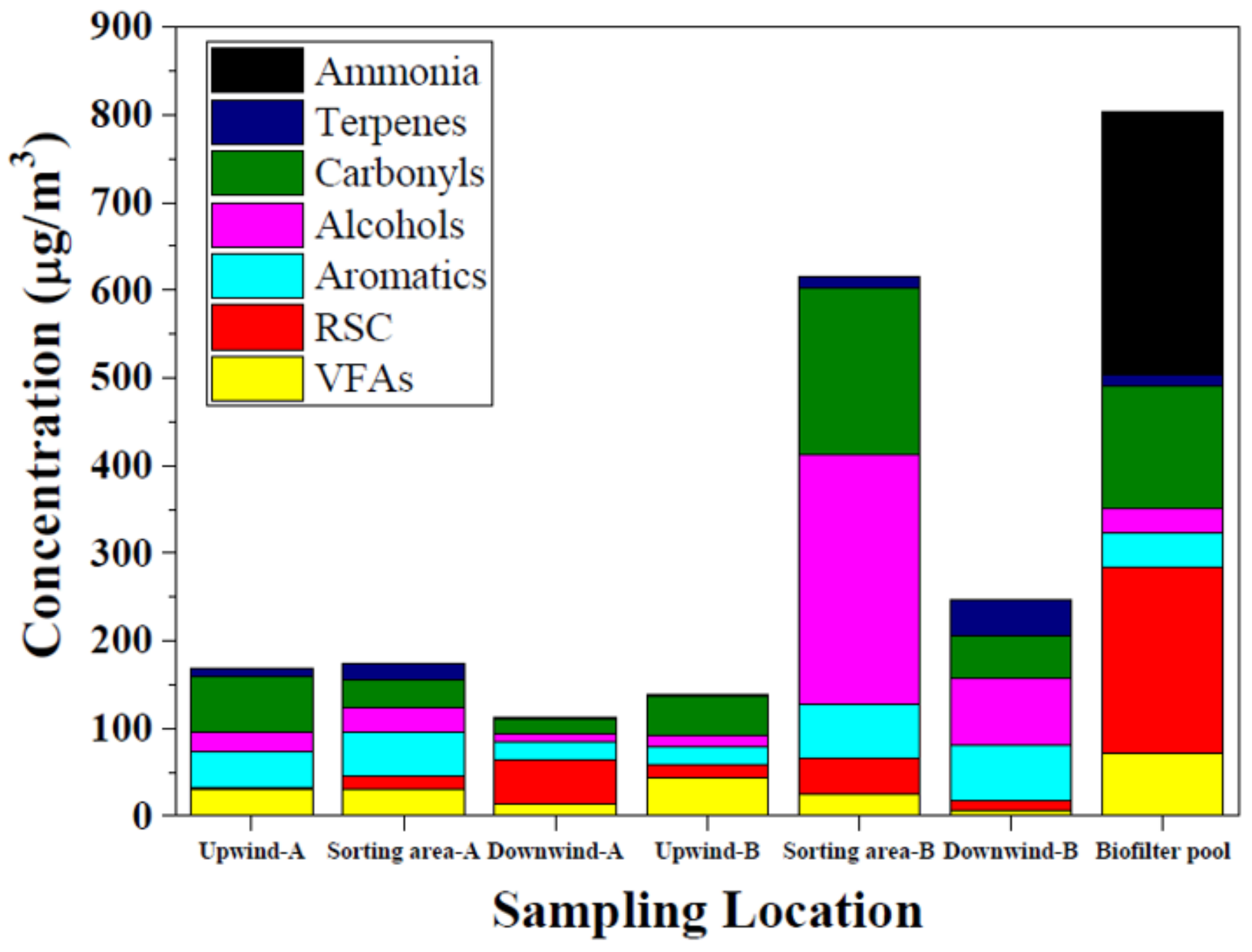

Figure 3

Total gaseous compounds in the facilities periphery. " $A$ " in $\mathrm{x}$ axis represent sampling without waste unloading and sorting operation, " $B$ " represent sampling during waste unloading and sorting operation. 

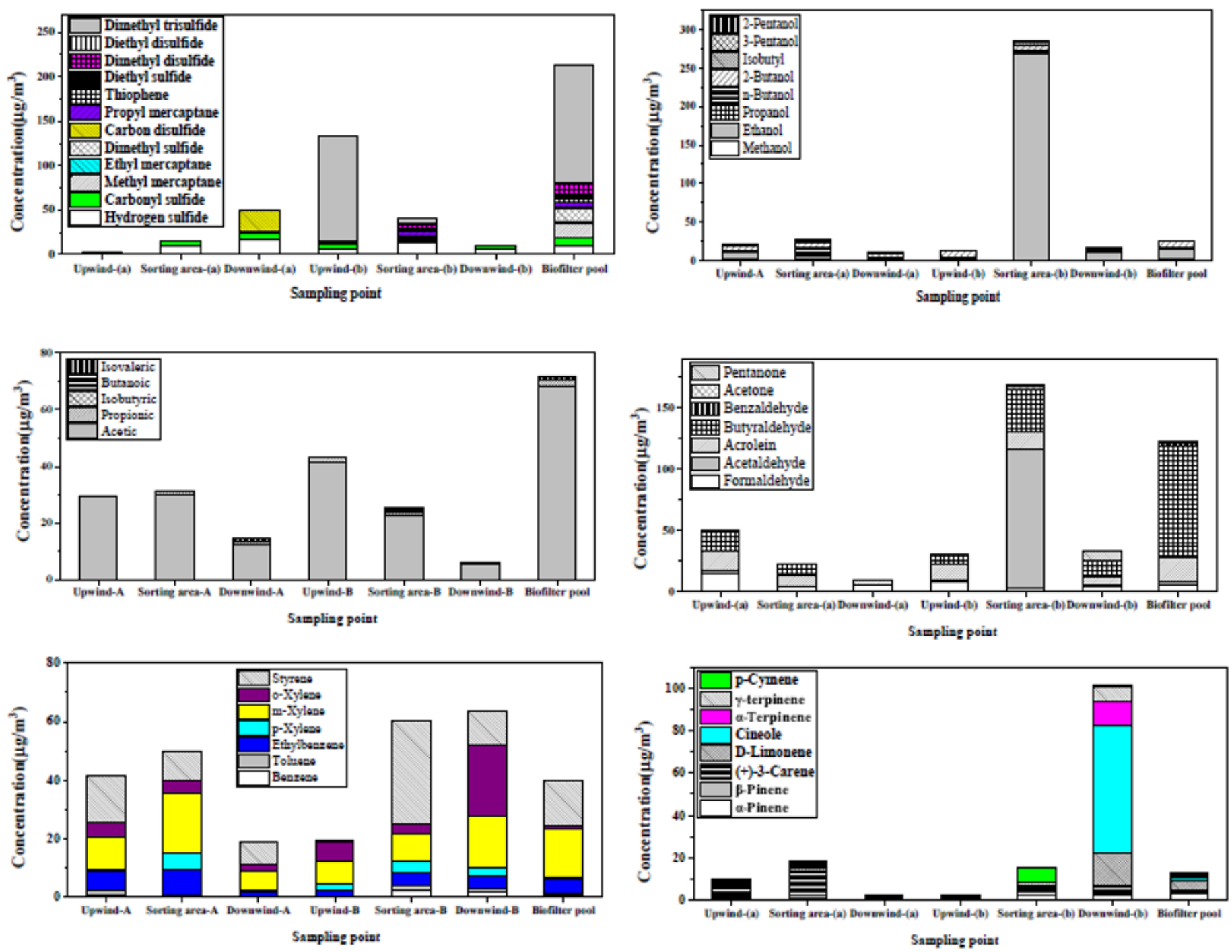

Figure 4

Composition of the gaseous compounds in the facilities periphery. " $A$ " in $\mathrm{x}$ axis represent sampling without waste unloading and sorting operation, " $B$ " represent sampling. 


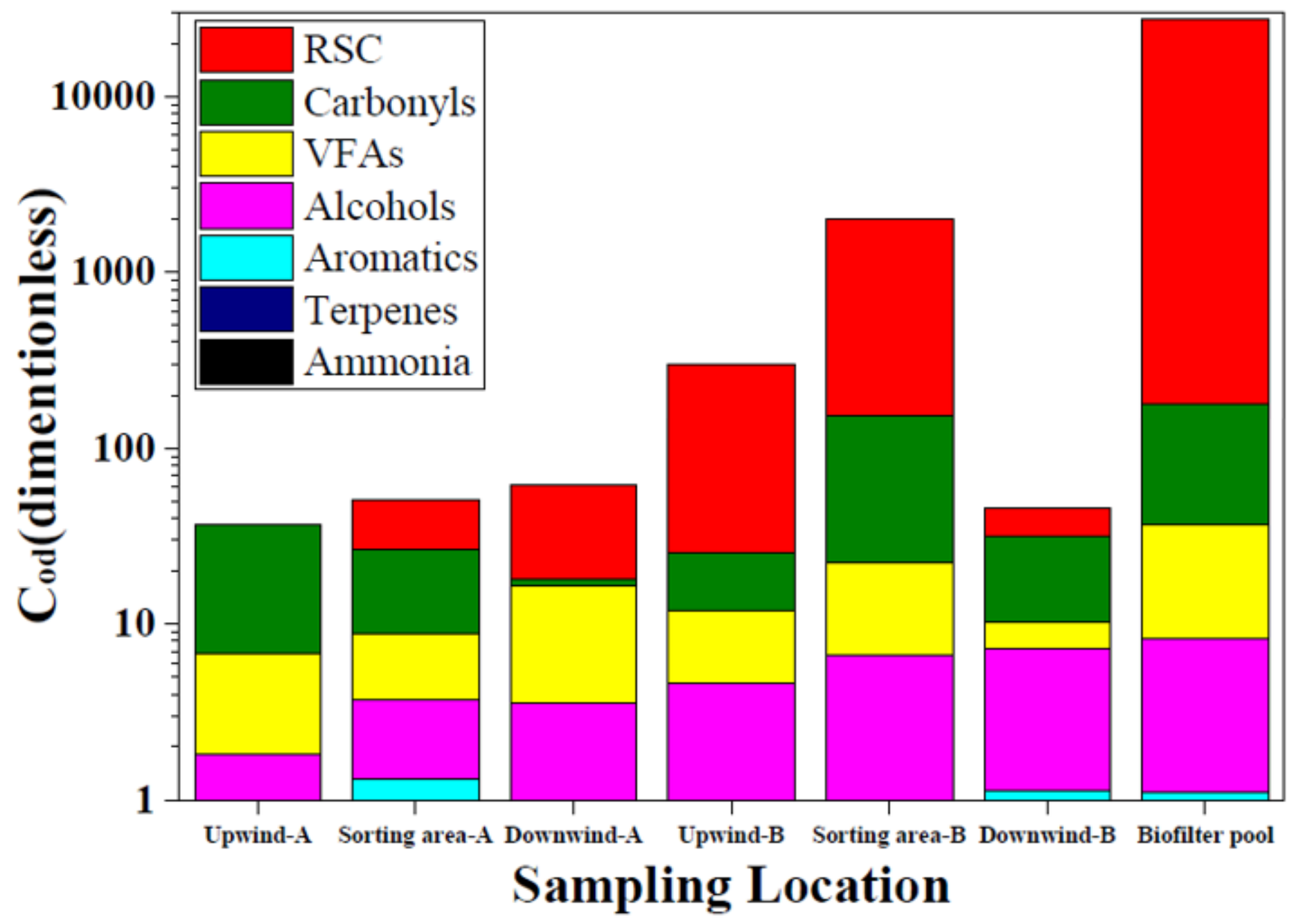

Figure 5

Theoretical odour concentrations of the odor compounds in the facilities periphery. " $\mathrm{A}$ " in $\mathrm{x}$ axis represent sampling without waste unloading and sorting operation, " $B$ " represent sampling during waste unloading and sorting operation. 


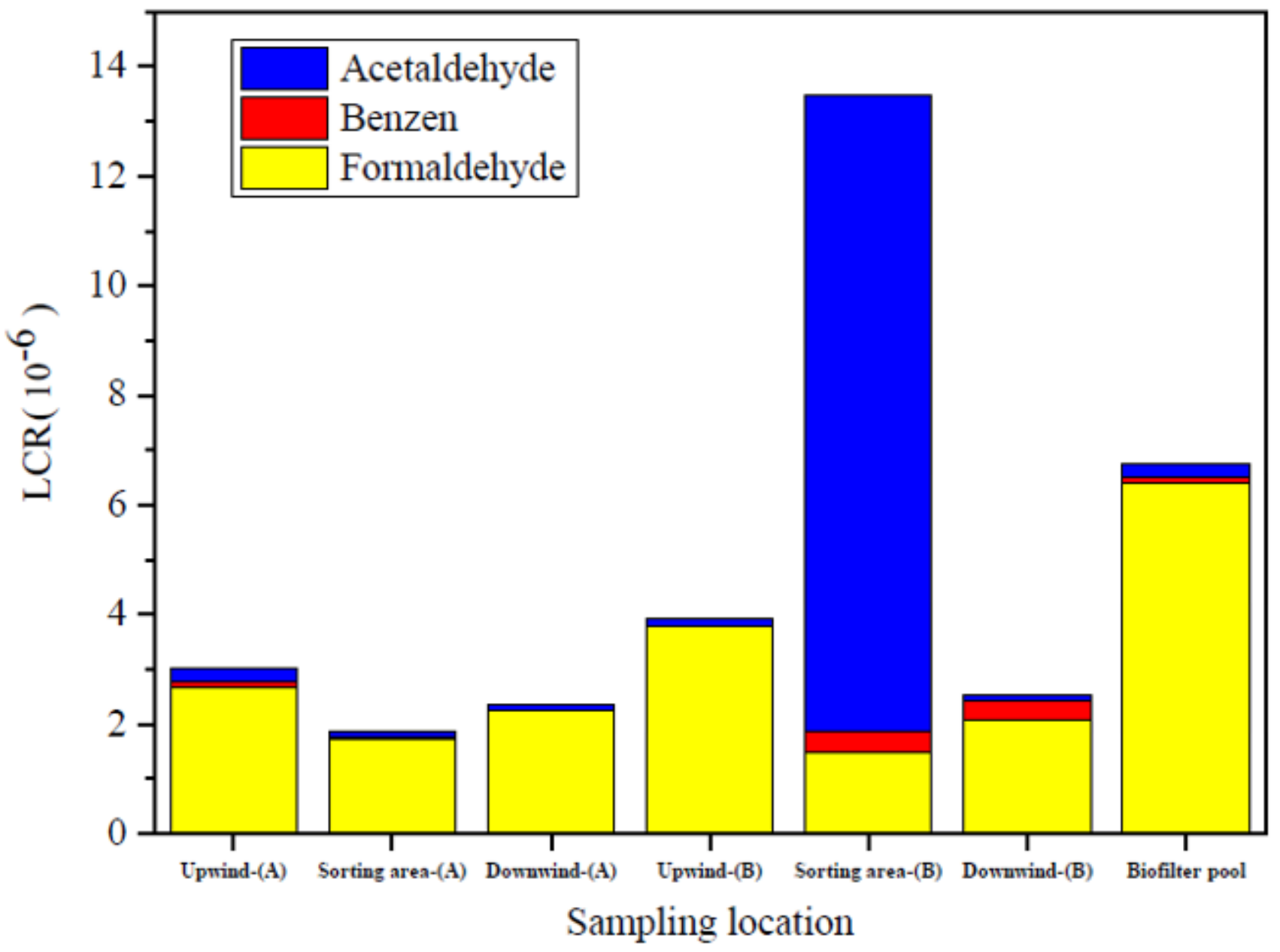

Figure 6

Carcinogenic risks from volatile compounds through inhalation in waste and non-waste areas of the MSW landfill. " $A$ " in $x$ axis represent sampling without waste unloading and sorting operation, " $B$ " represent sampling during waste unloading and sorting operation. 